\title{
Intergenerational Mentorship in Pedagogical Design and Delivery
}

\section{Introduction}

Existing scholarship exploring the notion of mentorship in academic environments typically reflects support for negotiating tenure (cf. Driscoll et al., 2009; Savage, Karp \& Logue, 2010; Waddell et al., 2016). In this context, mentorship is understood as a practice by which one person, usually of superior rank, acts as a role model and guides the professional development of a more junior individual (Savage, Karp, \& Logue, 2010). This unilateral notion of mentorship has been investigated in the field of tourism as seen in Williams et al.'s (2018) phenomenological study, whereby they explore what may constitute effective models of mentoring tourism faculty. Mentorship research has established the positive outcomes of interactions among junior and senior faculty in terms of socialization, job satisfaction, retention and the achievement of tenure (Bilimoria, Joy \& Liang, 2008; Waddell et al., 2016). However, absent from this research, and tourism literature more broadly, are discussions and analyses of reciprocated mentorship between junior faculty scholars and their graduate students.

In 2016, a core team of faculty members at a Canadian University co-designed an immersive, integrated project that was employed across two core-curriculum courses in their tourism program (Boluk, Muldoon \& Johnson, 2019a; Boluk, Muldoon \& Johnson, 2019b; Miller, Boluk, and Johnson, 2019). We, Junior Scholar (Karla - Assistant Professor) and Grad Student (Maggie - Lead Teaching Assistant and $\mathrm{PhD}$ Candidate), were integral to the team, as well as the success of the first iteration of this integrated curriculum design (ICD). The ICD was developed as an effort to create more relevant curriculum, responding to the needs of contemporary students, thus consciously focusing on skill development of our undergraduate students (Miller et al., 2019; Boluk et al., 2019a; 2019b). Positioned as an innovative, critical, and empowering pedagogical approach, our analysis of the initial ICD revealed that integration across courses fostered deep learning through peer-to-peer knowledge sharing, community engagement, and real-world application.

Indeed, the initial steps towards employing an ICD can seem overwhelming; yet the collegial dynamic and intergenerational partnership we established at the outset provided some solace. As Pharr (2000) suggested, we are often not alone in teaching these types of curricula; rather a team of faculty members and graduate students work in collaboration. Certainly collaborative environments and teaching teams can be a "source of collective wisdom" (Powell, 2013, p. 30), nevertheless, Richmond and colleagues (2013) caution that the success of such teams hinges upon transparent communication, a clear understanding of expectations, and reciprocal trust. These ideas were reified in our assessment of the "growing pains" associated with implementing an ICD (Miller, et al., 2019). Building from these discussions, and the insights we have gathered from our own intergenerational partnership, we use this reflexive paper to expand our pedagogical scholarship and consider notions of mentorship and intergenerational learning. Specifically, we draw on memory-work (cf. Kivel \& Johnson, 2009; Rouzrokh et al. 2017) and Creative Analytic Practice (CAP) (Parry \& Johnson, 2007) to explore the ways in which horizontal relationships may foster intergenerational learning, and thereby disrupt the hierarchical dynamics of traditional mentorship models. Moreover, we argue an intergenerational approach to learning creates a "mentorship" model that aligns with the 
changing undercurrents of academic landscapes, and may enhance the experiences of contemporary graduate students.

\section{Literature Review}

\section{Faculty and Graduate Mentorship}

Mentorship has been defined as “a process in which one person, usually of superior rank and outstanding achievement, guides the development of an entry-level individual” (Savage, et al., 2010, p. 21). Such traditional approaches to mentorship support a hierarchical relationship between a mentor/expert and their protégé (Driscoll et al., 2009). Specifically, traditional mentoring emphasizes the flow of "help, power, and resources" in a unilateral direction (Colvin \& Ashman, 2010, p. 131). Inherent in the language used to describe mentorship is a continuum of authority, thus reinforcing power of certain individuals, which as Tempest (2003) suggests, disincentives the sharing of knowledge, or a willingness to engage with new approaches of mentoring others.

Hierarchical relationships may surface unintentionally; sometimes this occurs in universities where established scholars engage and guide new faculty who may be a member of a minority group or women (Driscoll et al., 2009). The connections made between new and established faculty members likely tout benefits of network formation, whereby intellectual engagement, collaboration, and emotional support can lead to a sense of organizational fit (Lindholm, 2003). According to Louis (1990), the development of interpersonal relationships and social networks is a way for newcomers to learn from experienced coworkers about organization/department operations. Moreover, newcomer network development is "associated with a sense of integration and overall socialization experienced by new faculty” (Fleming et al., 2016, p. 567), and thus university departments should embolden mentoring relationships, encouraging senior faculty to check in on newcomers, as these pre-tenured faculty often benefit from such relationships.

Mentorship is not only formative for new faculty, but can also be an integral part of the graduate student experience, as well as an opportunity to better prepare students for the pressures of pre-tenure positions (cf. Austin, 2003; Eddy \& Gaston-Gayles, 2008). The work of Eddy and Gaston-Gayles (2008) and Austin (2003) explored the need to mentor graduate students to enhance doctoral training, in particular the transition from graduate students to faculty members. Specifically, Austin (2003) identified that many graduate programs do not support the development of aspiring faculty; aspiring faculty do not receive clear feedback from administration; graduate students do not understand what faculty positions require; and the quality of life for faculty members is questionable. Interestingly, Eddy and Gaston-Gayles' (2008) work revealed distinct differences between graduate students who "self-selected" mentorship, thereby making their intentions known to faculty members, and those who were regarded as the "chosen one[s]" and received invitations/introductions, training about faculty life, inclusion on research teams, and training on the publication process (p. 95). Accordingly, research is warranted to explore how faculty may better support graduate students. Specifically, understanding the ways in which intergenerational learning may be a conduit for sharing knowledge and experiences and thus may facilitate academic transitions. 


\section{Intergenerational partnerships \& Horizontal relationships}

Dialogue is democratic (cf. Freire, 1973; Shor, 1992) and knowledge - socially constructed. As such, mutually created discourses call attention to different types of knowledge, indicating an importance for academics to challenge power within workplace ranks and relationships. Tempest (2003) supports the notion of Intergenerational Learning, capturing the "potentially rich, reciprocal process of learning that builds from marrying the diverse knowledge bases of workers with different levels and types of work and life experiences (p. 183). Rather than reinforcing the roles of "mentor and mentee," intergenerational learning is based on the grounds that "everyone leads, and everyone learns" (Satterly, Cullen \& Dyson, 2018, p. 6, emphasis in original). Central to this approach are the informal and formal relationships developed (Satterly et al., 2018). Moreover, intergenerational learning emphasizes a co-creation of knowledge, implying “a reciprocal process of learning and knowledge development” (Bjursell, 2015, p. 285). Herein, reciprocity juxtaposes the one-sided knowledge transfer from older to younger generations (Tempest, 2003), and challenges the hierarchical approaches identified in traditional mentorship relationships (Smith et al., 2013).

This reciprocal nature of intergenerational learning is reflective of Freire's (1973) understanding of education as a "horizontal" relationship - where people talk mutually, instead of the teacher talking at students or down to them. Freire aligned horizontal relationships with a set of emotional values such as student-teacher camaraderie, or in our case cross-mentorship and reciprocity within an intergenerational partnership. Current educational literature supports the idea that students learn better when they are actively involved in their own learning, and that integrative and co-creation initiatives allow them to develop their potential (cf. Bergmark \& Westman, 2015; Bilous et al., 2018; Fenton \& Gallant, 2016; Lubicz-Nawrocka, 2018). This was illuminated in Lubicz-Nawrocka's (2018) study around the co-creation of curriculum with students. Central to the success of her non-traditional teaching approach was "respect for different opinions, reciprocity by sharing different (although not necessarily the same) expertise and perspectives, and responsibility shared amongst students and staff” (p. 58).

Similarly, in the mentorship literature, the establishment of reciprocal intergenerational learning offers “a more inclusive, egalitarian, and fluid approach to learning” between generations, emphasizing co-creating value (Bjursell, 2015, p. 290). Intergenerational learning has been recognized as a way to retain valuable expertise that has been generated over the years. As such, mentoring, and transferring knowledge are identified as effective strategies for managing concerns in relation to losing knowledge (Roodin \& Mendelson, 2013). Moreover, contemporary workplaces have acknowledged benefits in leveraging the expertise of their aging workers (e.g., Boomers) as they experience an influx of younger generations (e.g., millennials) who come with varying talents and skills (Chaudhuri \& Ghosh, 2012). Ultimately, intergenerational learning captures the diverse knowledge all individuals hold through their various work and life experiences, and recognizes opportunities that may emerge from working together and through co-creation practices.

Indeed, intergenerational learning presents an important avenue to further understand mentorship relationships that transpire in academic workplaces. More specifically, we are interested in exploring the collaborative opportunities and possibilities for reciprocity between a pre-tenured scholar and graduate student - a relationship we refer to as an intergenerational partnership throughout this paper. To do this, we employed memory-work and Creative Analytic Practice (CAP) methodologies to co-create and unpack three vignettes representing our experiences in employing an integrated curriculum design (ICD) across two core-curriculum 
courses in our tourism program. However, prior to explicating our methodological approach we first briefly discuss ICD, to provide context around the dynamic relationship that existed between us.

\section{Integrated Curriculum Design}

An ICD in higher education unites core degree courses supporting deep learning opportunities, while simultaneously leading students to be better collaborators empowering them to make a difference in the classroom, their communities, and society (Miller et al., 2019). Integral to this pedagogical approach are the mutual positions of teaching and learning between educators and students, and even practitioners from the community (cf. Anderson, 2013; Boluk, under review; Fenton \& Gallant, 2016). Integration and mutuality within learning environments supports engagement, action, and respect from both educators and students with an emphasis on empowering students (Fraser \& Bosanquet, 2006). In Lubicz-Nawarocka's (2018) work around ICD, she found that when instructors cede some of the control in how the classroom operates, students experience greater satisfaction and sense of personal achievement in their academic experiences. Correspondingly, students engaging this type of education have more positive perceptions of course instruction, content, and structure (Austin, Hirstein, \& Walen, 1997; Fenton \& Gallant, 2016; Paisley et al. 2013).

The ICD we employed was framed as a multi-phase project with several points of intersection between two tourism cohorts, including a first-year class and a fourth-year class. Students were tasked with responding to a challenge posed by our industry partner: How may local tourism businesses enhance the experiences of millennial consumers? Both cohorts of students visited one of five local attractions in order to fulfil their aspect of the project. First year students were positioned as expert users (of the tourism experience) and the fourth-year students were positioned as expert designers (in order to respond to the issues posed by the expert users). The points of intersection between the two groups included: (1) a joint guest lecture with our industry partner; (2) our $1^{\text {st }}$ years responding to a user experience survey created by our $4^{\text {th }}$ years; (3) a face-to-face focus group whereby $4^{\text {th }}$ year students checked their assumptions and preliminary analysis of the survey data with the $1^{\text {st }}$ years; and (4) formal presentations delivered by the $4^{\text {th }}$ year students to the $1^{\text {st }}$ year students and a panel of industry and community partners (Boluk et al., 2019a; 2019b,; Miller et al. 2019).

Through this project, we realized that integrating curriculum disrupts traditional education by challenging the "banking" approach to teaching, where the instructor is often positioned as the expert, and students as empty vessels waiting to be filled with knowledge (Ackoff \& Greenberg, 2008; Freire, 1973; Miller et al., 2019). Although many university faculties seemingly understand the value and appeal of these more reciprocal teaching methods, the process of implementing interdisciplinary programming like an ICD comes with its challenges. For example, the need for additional time and energy to develop and maintain an ICD and maintain connections with community partners (Boluk et al 2019a; 2019b; Miller et al., 2019). Furthermore, it became evident through this research that emerging scholars find it difficult to harness support to "play with pedagogy" (Powell et al., 2013, p. viii) - a conversation we return to in our discussion. However, first an overview of our choice to use memory-work and CAP to conduct this research. 


\section{Methodology}

Grounded in social constructionism, the scaffolding of our methodological approach embraces collective and participatory practices. Drawing inspiration from improvisational methodologies (cf. Berbary \& Boles, 2014), we employed creative methods that elicit understandings through collective memory-work (cf. Kivel \& Johnson, 2007; Small, 1999) and Creative Analytic Practice (CAP) (Parry \& Johnson, 2007) to critically reflect on the notion of intergenerational partnerships, and how our own experiences, as a junior scholar and graduate student, influenced the trajectory of our ICD project to its current form.

Collective memory-work is gaining traction in leisure and tourism studies (cf. Kivel \& Johnson, 2007; Rouzrokh, et al., 2017; Torabian \& Miller, 2017; Tung \& Ritchie, 2011) and social sciences more broadly. It enables research participants to recall, examine, and analyze memories and experiences within a broader cultural context (Kivel \& Johnson, 2007). Unique to this collaborative, qualitative methodology, is its affordance to engage participants in both data generation and analysis (Kivel \& Johnson, 2007). Furthermore, Thomsen and Hansen (2009) argue memory-work encourages an awareness of the social and cultural embeddedness of phenomena by "illuminating the culturally constructed I through a collective interpretation of individual memories.” (p. 27). Thereby, collective memory-work aligned well with the epistemological underpinnings of this project, and supports our intentions/values associated with an intergenerational partnership. Antecedents to this paper lie in our own experiences of mentorship with one another - a relationship that is much more reciprocal and horizontal, than it is hierarchical. Tung and Ritchie (2011) have noted that collective memory-work seeks to challenge the commonly held hierarchy that exists between researcher and participant. Similarly, drawing from their educational exercise, Torabian et al. (2014) recognized that memory-work can help to flatten power relations between professor/lecturer and student, lending to shared teaching and learning opportunities. Our own-shared learning was realized through our engagement with CAP, which provided a vehicle for us to express and analyze memories of our intergenerational partnership.

According to Berbary (2011), CAP has contributed to the growing body of work that characterizes itself as "art as research, research as art" (p. 194). Popular in social science disciplines including anthropology, education, sociology and women's studies, and more recently leisure studies (cf. Parry, 2007; Parry \& Johnson, 2007; Trussell, 2010; Yuen, 2010), CAP is used by researchers to produce political, evocative, collaborative, creative, decolonizing, and honest reflections on, and of, our social world. However, reflexive methodologies, and specifically CAP, are less visible in the field of tourism (notable exceptions include: Boluk et al., 2019a; 2019b, Miller et al., 2019; Wright, 2018;). Yet, Ellis and Bochner (2000) indicated that critical self-reflexivity, including what they refer to as "confessional tales," may help us to deepen understandings of tensions that may arise in the doing of research (p. 740; see also Gullemin \& Gillman, 2004). Accordingly, CAP is "writing as a method of inquiry, a way of finding out about yourself and your subject” (Richardson, 2000, p. 923). The arts-based methods of CAP differ from creative writing techniques, as CAP moves beyond the presentation of writing creatively, towards considering the act of writing itself, which is an important part of the research process (Boluk et al., 2019a). As such, a CAP research approach acknowledges that the writing process and product are interwoven and thus are not possible to separate (Richardson, 2000).

In many instances, CAP is used as a form of representation (cf. Parry, 2007; Trussell, 
2010). Richardson's (2000) work on CAP reflects on the dull, dreary, and uninspired writing up of qualitative inquiry. Thereby, CAP is presented as an alternative that allows writers to play with their writing style, uncovering new perspectives while also creating texts that are appealing to readers, including those outside of academia (Berbary, 2011; Denzin \& Lincoln, 2003; Richardson, 2000). Instead of attempting to condense study findings and fit with a particular theoretical framework, CAP encourages questioning and ongoing interpretation (Boluk et al., 2019a; Berbary, 2011; Richardson, 2000). Thus, we draw attention to the use of CAP as an innovative way to represent data within tourism studies, and to broaden the audience and impact of our discussions around mentorship.

\section{Data collection \& analysis}

Marshaled by a collaborative and collegial spirit, we began our data collection process, together, by identifying subtopics related to our own relationship, as well as our ICD work (e.g., how we met; challenges we encountered; etc.). Some of the subtopics were based upon notes we had taken in meetings, and emails we exchanged with one another and other project partners. We selected three topics to explore further, one from the beginning, middle, and end of our working relationship across the ICD. Then, we wrote memories about these topics, separately and in third person. Writing in third person is a practice used in collective memory-work, as it is said to historicize and create "some emotional distance" for narrators from their experiences, while forcing an explanation that is not self-evident (Fraser \& Michell, 2015, p. 330). Moreover, Johnson (2009) implied that making our lived stories visible to one another - and our audience may create a level of vulnerability; therefore, embracing "distance” from our memories by writing in third person made for an easier writing process.

After we drafted our memories individually, we came back together to collectively debrief the specific discourses that underpinned each particular memory, and the additional memories made manifest through our conversations. Interestingly, we had many similarities in our own recollections of the moments captured about each topic. However, to ensure representation of some of the differences, and the unique nature of our individual memories, we used CAP to construct creative composite memories. Such an approach initiated simultaneous roles of researcher and researched, in which our shared memories were analyzed, co-constructed and then re-storied into three creative vignettes. The environments and much of the details within the vignettes have been fictionalized, but in keeping with Richardson and St. Pierre's (2005) criteria for creating and evaluating CAP, we maintained attributes of aesthetic merit, reflexivity, impact, and substantive contribution. Lastly, we used these composite vignettes to critically reflect on the moments and interactions of which the memories represented, developing layered accounts for audience consideration (cf. Parry \& Johnson, 2007; Trussell, 2010). Overall, this analytical process occurred through two in-person meetings, four Skype phone calls, and several emails over the course of four months.

Indeed, CAP provided an opportunity for us to deeply engage with the material and topics through the creation of rich and evocative texts. Here our experiences and perceptions of the memories are made manifest, while simultaneously inviting audiences to draw their own conclusions (Berbary, 2011; Parry \& Johnson, 2007; Richardson, 2000). In this way, we hope our use of CAP "encourages involvement, inspires curiosity, creates inclusivity, and constructs depictions that remain in the thoughts of readers in ways that traditional representations sometimes do not” (Berbary, 2011, p. 194). 


\section{A re-storying of collective memories and intergenerational partnership}

\section{Vignette 1: Instigating Mentorship Opportunities}

Maggie's footsteps softened. She paused, took a deep breath, and then rounded the final corner into the bleak corridor. The office doors were all tightly closed with the exception of one. Light leaked onto the dull brown carpet through the crack of the door. Maggie straightened her long blue scarf, and tucked her hair neatly behind her right ear. "Ahem." She cleared her throat. "Karla ...I was hoping, I mean...I was wondering..." Maggie muttered quietly to herself as she cycled through her premeditated discussion points. At the door with a silver placard that read" "Dr. Karla Boluk, Assistant Professor, Department of Recreation \& Leisure Studies.” Maggie knocked compellingly.

The door swung open. Bright beams of sunshine flooded into the hallway. "Maggie! How are you?" Karla greeted cheerfully. "Please come in."

"I'm well, really great actually. How are you doing?"

“Oh good, glad to hear it. Yeah, I'm good, thanks!” Karla chimed back.

Maggie took a seat in the small armchair to the right of Karla's desk. Returning to her swivel chair in front of the double-screen computer monitor, Karla clicked her email inbox closed. "Thanks for agreeing to meet with me, I know you're busy this time of year."

Karla's eyes shifted from the computer to meet back up with Maggie's. "Don't mention it, I'm so glad you reached out!" Karla offered genuinely.

The room was silent for a moment.

Maggie leaned forward suddenly and launched into the explanation of her proposal, "So... as I mentioned in my last email, I am eager to teach this year. I'm in my third year of my PhD and don't have any classroom experience. I mean, I've taught, but that was the online version of the Intro to Tourism class. And since you teach the live version of the class, I thought maybe you would be interested... I mean, I was wondering if you could mentor me? Maybe I could be involved in the delivery of your course? Would you be interested in having me help out in some capacity next semester?" Maggie paused for a quick breath. "I don't know...Like a lead TA or a co-instructor? Something that involves a bit more responsibility than a regular Teaching Assistant."

Karla, attentively nodded along as Maggie highlighted her final point. Maggie's enhanced confidence was now apparent, even in her voice. "I mean I think what I am proposing could be mutually beneficial, I would gain teaching experience and mentorship in delivering a few lectures, and maybe contribute to assessment design?"

\section{Karla's Reflection}

The above vignette highlights how Maggie sought out my mentorship through her proposal to be a lead teaching assistant or co-instructor of the first-year introductory tourism course. Her proposal came at a pivotal time, well in advance of the start of the term, before I had formally 
begun to plan the administrative pieces of the course. I immediately sought the opinions of our department administrator and chair. They both responded favourably and approved the idea. I think the idea floated partly because I approached administration with a solution rather than a complaint about my teaching load (the class size was 350 students at the time). This idea was an outcome of Maggie's independent thinking. Clearly, she was keen to gain teaching and course design experience to prepare herself and enhance her CV for her own scholarly pursuits.

I was looking forward to the notion of having a small relief to teaching; would this mean that I would have more time to do research? Or would mentoring Maggie be burdensome? These sentiments of teaching relief, however, did not overshadow an insecurity I held onto in my pretenure position: I am tethered still, to my teaching evaluations. Memories of one of my $\mathrm{PhD}$ students in the UK bursting into tears because she thought a student was laughing at her in the middle of delivering a lecture resurfaced. How would I make sure a similar situation did not happen again? I wondered if I was the right mentor for Maggie, I wondered if she considered my job title critically? I am an Assistant Professor, and pre-tenure after all: would she benefit more from one of my more seasoned colleagues? I did not have the answer to all of these questions but was willing to take on the challenge. My pedagogical scholarship reflects values associated with caring, so here was a chance for me to practice what I preach. Investing in Maggie did not seem like a gamble given the trust we were establishing, and her notable caliber.

I thought of Maggie and my other seven teaching assistants as valuable resources; I was relatively new to the Canadian landscape, since having studied and worked in New Zealand and Europe for the previous 8 years. I was also looking forward to Maggie's insights into further developing our ICD. I was particularly impressed by her interest in pedagogical scholarship given the lack of emphasis in this area in a research-intensive university.

\section{Maggie's Reflection}

At the time of my request to co-teach with Karla, I did not know her very well. She had only arrived to the University half way through my tenure as a PhD student, so our one-to-one interactions were limited. This was likely a reason for some of my apprehension and nervousness when approaching her with the proposal. It was not that I considered Karla to be unapproachable, indeed she is very much the opposite, but the existing "hierarchy" - the faculty-graduate student dynamic - still felt intimidating to me. Concealing my concerns around power relations, and their broader effects within the academy, I knocked on her door anyhow; a decision rooted in my hope for mentorship and more classroom teaching exposure and experience. What I have come to appreciate about my $\mathrm{PhD}$ program were the opportunities that were available to teach as a graduate student (something I've recently learned is not the norm in all institutions). I believe this "on-the-job” training is integral to the development of graduates who anticipate an academic career, and it certainly facilitated an easier transition into my first full-time academic post. Yet being launched into a classroom by yourself can be overwhelming and anxiety-inducing. I knew this from observing fellow $\mathrm{PhD}$ peers, as they tried to juggle dissertation writing with the trials and tribulations that come with first time course prep and teaching. Thus, teaching along side Karla felt like a safe option, one in which we could share the roles and responsibilities of creating and delivering dynamic tourism content. Nevertheless, I could not help to wonder if she would trust me. Would she be willing to share her course with me? Over the years I witnessed colleagues and peers being quite protective of their teaching content - the corollary of increasing individualism within higher education. And if she did agree for me to join her, would she allow me to contribute or would I be a backseat passenger, passively learning from her? 
The aforementioned questions swirled in my mind that day in Karla's office. But I admired her critical and community-oriented pedagogical initiatives, and knew the prospect of working with her was worth more than all the uncertainties. In the end, Karla agreed for me to come on board, and I was thrilled! As the semester progressed, I found comfort in her inclusive and open approach to teaching and mentoring. She not only valued my feedback and ideas as an active contributor to the course, but she took great interest in the suggestions of the other graduates who assumed typical teaching assistant roles.

\section{Vignette 2: Learning from mistakes and mishaps}

Karla picked up her laptop bag and slung it over her left shoulder. Hustling through the staff lounge, she peered at her mobile phone: '9:55AM' brightly illuminated the front screen. As the screen faded back to black, she slipped the phone into her jean pocket. Down the stairs, Karla pushed through the final set of double doors and entered the department's first floor café. She scanned the tables. The place was packed, gushing with chatter and laugher. Maggie was already set up in the back corner near the window, headphones in ears with a subtle smile wiped across her face. As Karla approached her, she reflected on Maggie's energy, and her enthusiasm for innovative pedagogical practice. "It's palpable." She thought to herself. This has come as a pleasant surprise to Karla; mutually, given Maggie's final juncture in her PhD journey, and her continuous intrigue in pedagogical scholarship, which is clearly not a priority at a researchintensive university like theirs.

"Hiya!" Karla swiftly moved into the seat across from Maggie. "You're always at it aren't you!" Karla jested, remembering feeling much more exhausted during her own PhD than Maggie demonstrates, as she balances her lead TA role and dissertation writing.

“It's got to be done!” Maggie said positively with a chuckle.

"Your right, and it looks like you are nearly there!" Karla laughed. "Speaking of got to get done..." Karla used the segue to pivot the conversation. "We have to finalize our ideas for the integrated assignment for the $1^{\text {st }}$ year students."

"Yeah. Um...actually, an idea just came to me this morning." Maggie admitted sheepishly.

Eagerly, Karla leaned over the tabletop, ready to hear Maggie's fresh ideas on the integrated curriculum design.

Maggie began to explain, "What if we have the $1^{\text {st }}$ year students engage with social media as a way to reflect on their user experiences? You know, each student can then reflect on the attraction they visit, by highlighting both positive and negative experiences on social media review platforms."

Karla nodded yes in agreement with Maggie, but the expression on her face indicated some hesitation. "Yeah, that could be a possibility." She responded.

The $4^{\text {th }}$ year students are meant to act as the expert designers in the ICD assignment, where they could narrow in on, intervene and respond to, a specific breakage in the user 
experience at different tourism attractions within the region. But both Karla and Maggie weren't quite clear on how they might access data to conduct these evaluations.

"Maybe..." Maggie continued to clarify her thoughts, "Maybe these could be formatted as reviews posted on Trip Advisor, or some other similar media platforms. Then the reviews, along with a summary of their experiences could be given to the $4^{\text {th }}$ year students to analyze."

Karla's smile grew larger as she sat back into her chair. "Yes, okay... I think this could work," she indicated. "And it would be a fantastic way for us to position our students as 'expert users,' deliver timely feedback to industry professionals who may be interested in implementing the students' ideas, and ultimately enhance their service offering!”

"Yeah. I think so!" Maggie chimed enthusiastically. "And it could be a fun way for the two cohorts of students to work together, while thinking critically through the challenges at the attractions!"

"Yes! Yes, I like this idea!" Karla exclaimed as she sipped the last of her coffee, and returned the mug back to its place on the table. She sat in silence for a moment, smiling contently as she processed the final details of Maggie's suggested ICD assessment.

\section{Karla's Reflection}

The above narrative highlights the naïve consideration of introducing a new assessment to our ICD, especially while the course was already running. As the professor and more seasoned educator, I did not critically consider this assessment, which turned out to be an unfortunate oversight as the assignment turned into a fiasco, one with some ethical weight. Admittedly, I was entirely preoccupied with being creative and enhancing what we had already developed with our ICD, discovering new ways to reach and engage our students. One aspect of the assessment that I found particularly exciting was the opportunity to encourage our students to be responsible citizens on-line, especially in the politically divisive landscape and given the socio-political importance of some social media platforms. Yet, the "requirement" to have students submitting reviews online, when in hindsight we did not provide adequate training on responsible or appropriate postings, led to a series of essay-like trip reviews that were anything but helpful to our community partners. Some posts included academic references, and appeared as though they were planted on the various review platforms, thus appearing much longer than typical "authentic" posts. Our community partners, who were approached at the outset of our ICD (and asked to participate), were disappointed with this outcome as they felt as though the students' posts seemed fake.

Luckily, our community partners were happy with the student products overall, but we now realize that this could have significantly jeopardized our relationship (Boluk et al., 2019b). Ultimately, Maggie and I had to deal with the aftermath of these posts/reviews, an additional layer of unintended work for both our community partners and us. The results of our decision to carry forward with the trip review activity, demonstrated my lack of introspection and critical deliberation around the challenges of implementing a new assessment while the course was already underway in the term. Upon reflection, I now ask myself why I didn't first check with our partners in advance? This outcome required us to consider alternative student assessments for future ICD iterations.

\section{Maggie's Reflection}


Karla and I dialogued around many of the positive outcomes of using trip reviews as a way to encourage student engagement with community/industry partners, but we undoubtedly did not take enough time to reflect on some of the ethical considerations and challenges of this teaching method. In learning that our partners were displeased with student interactions on the media platforms, we began to assess the potential damaging effects that our decision had on their businesses. Though many of the reviews could be deemed as helpful, highlighting both the positive aspects of a given attraction and areas for improvement, the Internet itself promises farreaching exposure. So not only were some of the longwinded assessments perceived as "fake reviews," but the negative commentary posted by the students was publicly available, and highlighted possibilities for knock-on effects for the tourism attractions' sales and reputations. With this realization, I felt quite responsible for the challenges we faced with our community partners; after all, it was me who first pitched the trip review idea to Karla. At the time, I remember feeling quite vulnerable, as well as confused as how this could have ever happened: Was I in over my head? Was I ready to be developing student assessments? Why didn't Karla push back against this idea? How could we have overlooked such "obvious” challenges?

Though the oversight felt embarrassing in the moment, I suppose in some ways it has lent to some important lessons, both personally and pedagogically. Though Karla trusted me to take the reigns, I realised I still needed her expertise and teaching experience to help guide me as I continued to develop my own teaching capabilities and confidence in the classroom; theoretically, this is something that a team-teaching environment can help to cultivate. Secondly, this mishap prompted reflection on the nature of our ICD. For something to truly be integrative and cooperative, we should be engaging with the community from the outset. Indeed, in hindsight, this pedagogical revelation seems so obvious. Moving forward, our partners requested opportunities to help develop specific projects, as well as a chance to interact with the first-year students (those doing the trip reviews), rather than just at the end during the fourth-year students' pitch presentations (Boluk et al., 2019b). Karla and I both supported these ideas, and envisage such changes in future ICD iterations.

\section{Vignette 3: Recognizing Talent \& Creating Opportunities}

Karla rummaged through her bag to find her keys as she approached her office door. Maggie, clutching a freshly brewed herbal tea, simultaneously turned the corner towards Karla's office as the lock on the door clicked open. Karla glanced up. "Perfect timing, come on in!" she said cheerfully, motioning for Maggie to enter and have a seat.

As they each settled into their respective chair, Karla briefly reflected on how happy she was with the partnership they had cultivated. Placing her hands on her lap, she peered over at Maggie and extended sincerely, "I know we debriefed shortly after the term last year, but I just wanted to reiterate that the lead TA role you created worked out really well! And I think we could agree we learned a lot working together."

Maggie attentively nodded her head yes. "I couldn't agree more, Karla, thanks for bringing me on board!” Maggie responded enthusiastically as her large grin exposed the dimples carved into her cheeks.

Karla continued, "I was particularly appreciative to have someone to discuss the course with and build our ICD into something we can really be proud of." It was obvious how much Karla loved Maggie's passion and willingness to help, as well as her ability to 
connect with the students. "So, you won't be surprised that I put your name forward as the sole instructor for the Winter term offering this coming semester".

“Wow, really?” Maggie asked, as she sat up in her seat a bit taller.

"Yes, of course! I know you'll be great." Karla's voice grew louder with enthusiasm. Rocking forward in her seat, Karla leaned onto the small round table that was set between them. "As you know, I will be going on maternity leave from the end of February and I think it is important we have someone in place who is knowledgeable about our vision for our ICD," she explained. "And, if it's going to be a success over the long-term, we have to maintain the already existing relationships with our community partners."

Maggie's smile stretched larger, as the meaning of Karla's words began to settle. "Wow, I wasn't expecting that, but I am delighted." The pace of Maggie's speech slowed, as she admitted, "Of course I feel a bit nervous, but I am up for the challenge. And after working so closely with you last year, and having experience with the Online version and years of TA experience, I think I'm ready."

"You are definitely ready! If you have any doubts. I will be a phone call a way. And I'll be sharing all of the resources and teaching materials with you via LEARN and Dropbox, so there's nothing to worry about." Karla reaffirmed. "Also, I wanted to mention," She continued, "I know you've begun to apply for jobs, I'll be happy to serve as a reference for you, anytime, now that I have seen you in action!"

Maggie smiled contently. She peered out the office window, into the distance. Whisked away in a daydream, she saw herself at the front of the lecture theatre, "Good afternoon everyone, I'm Maggie Miller and I'll be your instructor this semester..." As her attention returned to Karla, Maggie couldn't hide the excitement from her face. She was finally gaining the classroom teaching experience she had been wishing for - "I have big shoes to fill" she thought as she sipped her tea and basked in the future possibilities.

\section{Karla's Reflection}

Although an unintended consequence, Maggie's bold move to seek out mentorship led to my first-hand experiencing of her strengths. Witnessing here capabilities evolved into my advocacy on her behalf to teach the first-year course in my absence. When Maggie was a lead TA, we learned together from our mistakes, such as the trip review postings on social media platforms. Our discussions on how to improve this component of the course benefited our design overall. The work that we both put into considering alternative assessments demonstrated reciprocity and an equal partnership as we continually engaged in dialogue and sought out insights from one another. Following the trip review posting mishap, I reached out to our community partners interested in exploring more deeply how they were experiencing our ICD. This curiosity led to several one-on-one interviews following our ICD at the end of the term (Boluk et al., 2019b). Carrying out these interviews allowed us to gain further understandings around what may provide more benefits to our partners (e.g., instead of sharing student essays in regard to their interventions and recommendations, a succinct report detailing the suggested improvements would be more appropriate; see for example, Boluk et al., 2019b). The end of term interviews perhaps modelled best pedagogical practice, as well as how we may consciously reflect on our pedagogical practice and share our experiences in our scholarly writing. I hoped that actively seeking out the insights of our community partners demonstrated to Maggie the importance of 
taking care of community partnerships and the work needed to continually improve what we were doing in the classroom.

\section{Maggie's Reflection}

The opportunity to step into Karla's shoes, while she was away on maternity leave, was one of the unanticipated outcomes of my initial request for mentorship, to co-teach with her, and the relationship we developed over the teaching term. Her trust in me had become evident when she nominated me for a TA award I ended up winning within our faculty. Our work together was not without some bumps along the way. She became one of my strongest advocates during the final year in my $\mathrm{PhD}$, affording me the confidence I needed to juggle academic life - that is being equipped to research and teach simultaneously. Additionally, my partnership with Karla helped me to realize the value of engaging students in novel and creative ways. The ICD project not only lent to a ripe and innovative curriculum for future student cohorts in our department, but also helped to distinguish me as an emerging scholar and pedagogue as I started to apply and interview for academic positions.

Now sitting in a full-time post at another institution, I reflect on what I gleaned from our intergenerational partnership. Being untenured, I understand how much risk Karla may have taken to bring me under her wing. However, the value and rewards made those risks worth it. In the end, Karla was able to facilitate a nurturing environment for me to learn from and with her, while my keen and eager attitude pushed her to be more reflexive about her own teaching practices. Her openness made me feel valued, and in turn empowered me to contribute to the curriculum rather than being a passive teaching assistant, marking scripts from the sidelines. Indeed, our cross-mentoring dynamic highlighted the benefits that can be derived from team teaching (including teaching relief for faculty members) and the ways that these reciprocal and horizontal relationships might help bridge the gap for graduates who might not yet be ready to "go it alone" in classroom contexts.

\section{Discussion and Concluding Thoughts}

The aim of this paper was to draw on memory-work and CAP to explore ways in which horizontal partnerships may foster intergenerational learning and disrupt the hierarchical dynamics of traditional mentorship models. Specifically, we examined the partnership cultivated between a pre-tenured scholar and a doctoral graduate student. The mentorship literature draws attention to notions of power and hierarchical relationships between experts and their protégés (Driscoll et al., 2009; Savage, Karp, \& Logue, 2010). As such, in traditional mentorship cases there is unilateral flow of assistance to the less experienced colleague (Colvin \& Ashman, 2010). Reciprocity, while absent in our understandings of traditional mentorship cases, is the focus of intergenerational learning approaches (Bjursell, 2015). This was demonstrated by the horizontal learning that occurred during our time co-constructing an ICD in our tourism program. More specifically, mutual benefits and opportunities emerged within our partnership through Karla's openness to Maggie joining her as a Lead TA, and Maggie's active role in co-creating course curriculum. 
We have learned a great deal from each other through the process of designing, executing and delivering an innovative pedagogical design integrating two courses. Intergenerational learning emphases an inclusive, and fluid approach to learning, which equally values the knowledge of those involved, independent of their age, and various life and work experiences (Bjursell, 2015). This approach to mentorship allowed us to both step back and realize that neither of us were the purveyors of all knowledge (Freire, 1970), and thus we learned from each other, which ultimately benefited the development of our ICD to its current form. While we are close in age, our time in the academy, disciplinary training, work experiences and knowledge are distinct. Our vignettes and reflections illustrate our insecurities, concerns, mistakes, successes, as well as a reciprocal partnership of co-learning and cross-mentorship, which required us to draw on each other's strengths. This working partnership helped us to establish trust in each other, our experiences, and collaborative efforts to enhance the delivery of our ICD. Moreover, coauthoring this paper has afforded us with time to critically reflect on our actions, behaviours, decision-making and experiences around our ICD.

Our vignettes and subsequent reflections blend the formal with the informal as we were able to get to know each other outside of our prescribed and distinctive institutional roles: faculty member and graduate student. We continue to draw on each other's insights, knowledge, and experiences now that Maggie has taken up her inaugural academic position in the UK. We contend that our co-construction of an intergenerational partnership, and the mutual mentorship we provided (and continue to provide) to one another, could serve as an exemplar of what could be, or what should be, the process of contemporary scholarly environments. As Karla discussed in her initial reflection, balancing the pressures of pre-tenure while making outstanding contributions to scholarship, teaching, and service may fuel anxieties and uncertainties. Sharing such experiences with graduate students may mutually expose them to the realities of the job, while also identifying strategies to navigate such pressures. As noted in the literature review, there is paucity of scholarship exploring faculty-graduate student mentorship (cf. Austin, 2003; Gaston-Gayles, 2008). Perhaps the lack of research in this area is a consequence of the taxing demands on the role of the contemporary professor; for example, the neoliberal pressures dictating how we present our productivity to administration each year (Rose \& Dustin, 2009). Undoubtedly, a mentoring role does not necessarily earn faculty credit towards tenure, or recognition among the three prescribed areas in which professors are evaluated (research, teaching and service). However, we argue that developing partnerships is an important piece in the training of graduate students contributing to more confident, less anxious, better-prepared scholars who are equipped to carry out the demands of their future jobs.

While the literature presents a distinction between those graduate students who self-select mentorship and those who are chosen (Eddy \& Gaston-Gayles, 2008), our vignettes convey evidence of the potential opportunities that come from graduates self-selecting faculty mentors based upon who they think they may work well with. In our particular case, the partnership was cultivated outside of the graduate supervisory relationship and chosen by Maggie. Empowering graduate students to seek out relationships beyond their graduate committees holds merit for learning from a variety of faculty members. Additionally, we recognise that many graduate students receive little to no pedagogical training while completing their dissertation, and are often launched into teaching a full course on their own due to departmental teaching needs. Through our collective-memory work, it began apparent that our partnership led to an easier transition for Maggie when asked to eventually take on her own course. Thereby, we encourage 
others to engage in what we have proposed here, and find ways to better prepare all graduate students for tenure-track positions.

From a methodological standpoint, our creative methods and expressions are a departure from traditional empirical pieces; however, we are familiar with CAP and the benefits of engaging with memory-work (Boluk et al., 2019a; 2019b; Torabian \& Miller, 2017). While we realize that CAP approaches may be a detour for some scholars, it was utilized here to illustrate our memories of the processes and experiences we had working together, fostering intergenerational learning. Moreover, our reflections following each of the vignettes was a way to critically interrogate the activities which took place, and aided in a self-reflexive process that led to a deeper understanding of the complex and dynamic nature of our relationship, and its contexts (Ellis \& Bochner, 2000; Gullemin \& Gillman, 2004). The creative ways in which we have chosen to represent our experiences and work together here were intentional as they present honest reflections of our work together. We hope our work will inspire other recreation and tourism scholars to take up such creative methodologies.

Indeed, an intergenerational partnership could be a best practice for other departments/universities in that it may provide some teaching relief, while honing the capabilities of the next generation. Moreover, our creative vignettes and reflections demonstrated how our horizontal relationship celebrated the knowledge and experiences of us both. Specifically, we were able to recognize the valuable contributions of Karla, who may not have been deemed "mentorship material" due to her age and rank, and Maggie, a graduate student, still in training. It was our openness and willingness to learn from each other, and the integrative curriculum design that brought us as scholars together. Our intergenerational approach to learning presented here extends a new model, perhaps more appropriate, to the changing dynamics of contemporary academic landscapes. 


\section{References}

Ackoff, R. L. \& Greenberg, D. (2008). Turning Learning Right Side Up. Upper Saddle River, New Jersey: Prentice Hall. Anderson, D. M. (2013). Overarching goals, values, and assumptions of integrated curriculum design. SCHOLE: A Journal of Leisure Studies and Recreation Education, 28(1), 1-10.

Austin, J. D., Hirstein, J., \& Walen, S. (1997). Integrated mathematics interfaced with science. School Science and Mathematics, 97(1), 45-49.

Austin, A. E. (2003). Creating a bridge to the future: Preparing new faculty to face changing expectations in a shifting context. Review of Higher Education, 26, 119-144.

Berbary, L. (2011). Poststructurally writerly representation: Screenplay as creative analytic practice. Qualitative Inquiry, 17(2), 186-196. doi:10.1177/1077800410393887

Berbary, L. A., \& Boles, J. C. (2014). Eight points for reflection: Revisiting scaffolding for improvisational humanist qualitative inquiry. Leisure Sciences, 36(5), 401-419.

Bergmark, U. \& Westman, S. (2016). Co-creating curriculum in higher education: Promoting democratic values and a multidimensional view on learning. International Journal for Academic Development, 21(1), p. 28-40.

Bilous, R., Hammersley, L. Lloyd, K., Rawlings-Sanaei, F., Downey, G., Amigo, M., Gilchrist, S., Baker, M. (2018). 'All of us together in a blurred space': Principles for co-creating curriculum with international partners. International Journal for Academic Development, 23(3), p. 165-178.

Bilimoria, D., Joy, S., \& Liang, X. (2008). Breaking barriers and creating inclusiveness: Lessons of organizational transformation to advance women faculty in science and engineering. Human Resource Management, 47(3), 423-441.

Bjursell, C. (2015). Advancing the field organizing for intergenerational learning and knowledge sharing. Journal of Intergenerational Relationships, 13, 285-301.

Bynum, B. (2011). Sustainability in hospitality and tourism education: Towards and integrated curriculum. Journal of Hospitality and Tourism Education, 23(4), p. 22-31.

Boluk, K. A., Muldoon, M. L., \& Johnson, C. W. (2019a). Bringing a politics of hope to the tourism classroom: exploring an integrated curriculum design through a creative and reflexive methodology. Journal of Teaching in Travel \& Tourism, 19(1), 63-78.

Boluk, K., Muldoon, M. L., \& Johnson, C. W. (2019b). Co-creating an integrated curriculum alongside community partners: a creative analytic approach. Tourism Recreation Research, doi.org/10.1080/02508281.2019.1576962

Chaudhuri, S., \& Ghosh, R. (2012). Reverse mentoring: A social exchange tool for keeping the boomers engaged and millennials committed. Human Resource Development Review, 11(1), 55-76.

Colvin, J. W., \& Ashman, M. (2010). Roles, risks, and benefits of peer mentoring relationships in higher education. Mentoring \& Tutoring: Partnership in Learning, 18(2), 121-134.

Denzin, N., \& Lincoln, Y. (2003). Strategies of Qualitative Inquiry (2nd ed.). Thousand Oaks, CA: Sage Publications.

Driscoll, L. G., Parkes, K. A., Tilley-Lubbs, G. A., Brill, J. M., \& Pitts Bannister, V. R. (2009). Navigating the lonely sea: peer mentoring and collaboration among aspiring women scholars. Mentoring \& Tutoring: Partnership in Learning, 17(1), 5-12. 
Eddy, P. L., \& Gaston-Gayles, J. L. (2008). New faculty on the block: Issues of stress and support. Journal of Human Behavior in the Social Environment, 17(1-2), 89-106.

Ellis, C., \& Bochner, A. (2000). Autoethnography, personal narrative, reflexivity: Researcher as subject. In N. Denzin \& Y. Lincoln (Eds.), Handbook of qualitative research (2nd ed., pp. 733-768). Thousand Oaks, CA: Sage.

Fenton, L. \& Gallant, K. (2016). Integrated experiential education: Definitions and a conceptual model. The Canadian Journal for the Scholarship of Teaching and Learning, 7(2), 1-15.

Fleming, S. S., Goldman, A. W., Correll, S. J., \& Taylor, C. J. (2016). Settling In: The Role of Individual and Departmental Tactics in the Development of New Faculty Networks. The Journal of Higher Education, 87(4), 544-572.

Fraser, S. P., \& Bosanquet, A. M. (2006). The curriculum? That's just a unit outline, isn't it? Studies in Higher Education, 31(3), 269-284.

Fraser, H., \& Michell, D. (2015). Feminist memory work in action: Method and practicalities. Qualitative Social Work, 14(3), 321-337.

Freire, P. (1973) Education: The Practice of Freedom. London: Writers and Readers Publishing Cooperative.

Fuentes, M. V., Alvarado, A. R., Berdan, J., \& DeAngelo, L. (2014). Mentorships matters: Does early faculty contact lead to quality interaction? Research in Higher Education, 55, 288307.

Guillemin, M., \& Gillam, L. (2004). Ethics, reflexivity, and 'ethically important moments' in research. Qualitative Inquiry, 10(2), 261-280.

Johnson, C. W. (2009). Writing ourselves at risk: Using self-narrative in working for social justice. Leisure Sciences, 31, 483-489.

Kivel, B. D., \& Johnson, C. W. (2009). Consuming media, making men: Using collective memory work to understand leisure and the construction of masculinity. Journal of Leisure Research, 41(1), 109-133.

Lindholm, J. A. (2003). Perceived organizational fit: Nurturing the minds, hearts, and personal ambitions of university faculty. The Review of Higher Education, 27(1), 125-149.

Louis, M. R. (1990). Newcomers as lay ethnographers: Acculturation during socialization. In B. Schneider (Ed.), Organizational Climates and Cultures (pp. 85-129). San Francisco: Jossey-Bass.

Lubicz-Nawrocka, T. (2018). From partnership to self-authorship: The benefits of co-creation of the curriculum. International Journal for Students as Partners, 2(1), p. 47-63.

Miller, M. C., Boluk, K. A., \& Johnson, C. W. (2019). 'Lift off!’: Employing an integrated curriculum design to increase student, faculty, and community engagement. Journal of Hospitality, Leisure, Sport, \& Tourism Education, 25, https://doi.org/10.1016/j.jhlste.2019.100203

Paisley, K., Spencer, C., Wells, M. S., \& Schwab, K. (2013). The University of Utahs Integrated Core: A Case Study from a Commuter Campus. SCHOLE: A Journal of Leisure Studies And Recreation Education, 28(1), 54-63. 
Parry, D. (2007). 'There is life after breast cancer’: Nine vignettes exploring dragon boat racing for breast cancer survivors. Leisure Sciences, 29, 53-69.

Parry, D., \& Johnson, C. W. (2007). Contextualizing leisure research and encompassing complexity in the lived leisure experience: The need for creative analytic practice. Leisure Sciences, 29(2), 199-130.

Pharr, S. W. (2000). Foundational considerations for establishing an integrated business common core curriculum. Journal of Education for Business, 76(1), 20-23.

Powell, G. (2013). Continuum of collaboration: Little steps for little feet. SCHOLE: A Journal Of Leisure Studies And Recreation Education, 28(1), 24-31.

Richardson, L. (2000). Writing: A method of inquiry. In: N. Denzin \& Y. Lincoln (Eds.). The Handbook of Qualitative Research (2nd ed., pp. 923-948). Thousand Oaks, CA: Sage Publications.

Richmond, L. P., Anderson, M. A., Tucker, T. W., \& Powell, G. M. (2013). Navigating the role of graduate student on the teaching team. SCHOLE: A Journal of Leisure Studies And Recreation Education, 28(1), 88-97.

Richardson, L., \& St. Pierre, E. A. (2005). "Writing: A method of inquiry”. In Handbook of Qualitative Research (eds.). N. K. Denzin, and Y. S. Lincoln (959-978). Thousand Oaks, CA: Sage.

Roodin, P., \& Mendelson, M. (2013). Multiple generations at work: Current and future trends. Journal of Intergenerational Relationships, 11, 213-222.

Rose, J. \& Dustin, D. (2009). The neoliberal assault on the public university: The case of recreation, park, and leisure research. Leisure Sciences, 31(4), 397-402.

Rouzrokh, M., Muldoon, M., Torabian, P., \& Mair, H. (2017). The memory-work sessions: Exploring critical pedagogy in tourism. Journal of Hospitality, Leisure, Sport \& Tourism Education, 21(Part B), 163-173.

Satterly, B. A., Cullen, J., \& Dyson, D. A. (2018). The intergenerational mentoring model: an alternative to traditional and reverse models of mentoring. Mentoring \& Tutoring: Partnership in Learning, 26(4), 441-454.

Savage, H. E., Karp, R. S., \& Logue, R. (2010). Faculty mentorship at colleges and universities. Journal of College Teaching, 52(1), 21-24.

Shor, I. (1992). Empowering education critical teaching for social change. Chicago: The University of Chicago Press.

Small, J. (1999). Memory-work: A method for researching women's tourist experiences. Tourism Management, 20(1), 25-35.

Smith, E. R., Calderwood, P. E., Dohm, F. A., \& Lopez, P. G. (2013). Reconceptualizing faculty mentoring within a community of practice model. Mentoring \& Tutoring: Partnership in Learning, 21(2), 175-194.

Tempest, S. (2003). Intergenerational learning: A reciprocal knowledge development process that challenges the language of learning. Management Learning, 34(2), 181-200.

Thmsen, T. U., \& Hansen, T. (2009). The application of memory-work in consumer research. Journal of Consumer Behaviour, 8(1), 26-39.

Torabian, P. \& Miller, M. C. (2017). Freedom of movement for all? Unpacking racialized travel experiences. Current Issues in Tourism, 20(9), 931-945. 
Torabian, P., Muldoon, M., Rouzrokh, M., \& Mair, H. (2014). Critical pedagogy and transformational learning in tourism: Exploring the promise of memory-work. In Proceedings of Tourism Futures Education International Conference. Guelph, Ontario.

Trussell, D. E. (2010). Gazing from the inside out during ethically heightened moments. Leisure Studies, 29 (4), 377-395.

Tung, V. W. S., \& Ritchie, J. R. B. (2011). Exploring the essence of memorable tourism experiences. Annals of Tourism Research, 38(4), 1367-1386.

Waddell, J., Martin, J., Schwind, J. K., \& Lapum, J. L. (2016). A faculty-based mentorship circle: positioning new faculty for success. Canadian Journal of Higher Education, 46(4), 60-75.

Williams, J. A., Benjamin, S., Kitterlin-Lynch, M., Brown, E. A., Schoffstall, D., Zaman, M. (2018). Hospitality faculty mentoring program for assistant professors. Journal of Hospitality \& Tourism Education, DOI: 10.1080/10963758.2018.1486198

Wright, R. K. (2018). 'Doing it for dot': Exploring active ageing sport tourism experiences through the medium of creative analytical practice. Journal of Sport \& Tourism, 22(2), 93-108. doi:10.1080/14775085.2018.1466349

Yuen, F. (2010). Kicking and screaming. International Review of Qualitative Research, 2(4), 429-432. 